\title{
Beyond acne: Current aspects of sebaceous gland biology and function
}

Christos C. Zouboulis ${ }^{1}$, Mauro Picardo ${ }^{2}$, Qiang Jư ${ }^{3}$, Ichiro Kurokawa ${ }^{4}$, Dániel Töröcsik ${ }^{5}$, Tamás Bíró $^{6}$, Marlon R. Schneider ${ }^{7}$

${ }^{1}$ Departments of Dermatology, Venereology, Allergology and Immunology, Dessau Medical Center, Dessau, Germany

${ }^{2}$ San Gallicano Dermatologic Institute, IRCCS, Rome, Italy

${ }^{3}$ Department of Dermatology, Renji Hospital, Shanghai Jiaotong University School of Medicine, Shanghai, PR China

${ }^{4}$ Department of Dermatology, Meiwa Hospital, Nishinomiya, Japan

${ }^{5}$ Department of Dermatology, Faculty of Medicine, University of Debrecen, Debrecen, Hungary ${ }^{6}$ Department of Immunology, University of Debrecen, Debrecen, Hungary

${ }^{7}$ Institute of Molecular Animal Breeding and Biotechnology, Gene Center, LMU Munich, Munich, Germany

Correspondence should be addressed to:

Prof. Dr. med. Prof. h.c. Dr. h.c. Christos C. Zouboulis

Departments of Dermatology, Venereology, Allergology and Immunology, Dessau Medical Center, Auenweg 38, 06847 Dessau, Germany

Tel.: +493405014000

Fax: +49-340-5014025

christos.zouboulis@klinikum-dessau.de 


\begin{abstract}
The sebaceous gland is mostly found in association with a hair follicle. Its traditional function is the holocrine production of sebum, a complex mixture of lipids, cell debris, and other rather poorly characterized substances. Due to the gland central role in acne pathogenesis, early research had focused on its lipogenic activity. Less-studied aspects of the sebaceous gland, such as stem cell biology, the regulation of cellular differentiation by transcription factors, the significance of specific lipid fractions, the endocrine and specially the neuroendocrine role of the sebaceous gland, and its contribution to the innate immunity, the detoxification of the skin and skin aging have recently attracted the attention of researchers from different disciplines. Here, we summarize recent, multidisciplinary progress in sebaceous gland research and discuss how sebaceous gland research may stimulate the development of novel therapeutic strategies targeting specific molecular pathways of the pathogenesis of skin diseases.
\end{abstract}

Key words: Sebaceous gland; human; sebocyte; cells; sebaceous lineage; progenitor cells; sebaceous differentiation;ebum is characterized by specific lipid; lipidomics; cell function; neuropeptides; culture models, in vitro, ex vivo, proteom, secretom 


\section{Introduction}

The human sebaceous gland (SG) is a microscopic, branched type of multiacinar gland present everywhere on the body except on the palms, soles, and the dorsum of the feet [1]. Most SGs are multilobular glands; their three-dimensional structure resembles heads of cauliflower bound to a hair shaft. The cells within the acini show a characteristic centripetal enlargement. The individual acini empty into ducts that converge to a common excretory duct and this opens inside the pilary canal. The gland is surrounded by a connective tissue sheath rich in collagen fibers and fibroblasts. This sheath generates a trabecular system that separates the individual acini and offers a supportive stroma.

The SG belongs to a structure known as pilosebaceous unit (PSU), which also includes the hair, the hair follicle, and the arrector pili muscle [2]. Sebocytes are the major cells within SGs. Their purpose is the production and secretion of an oily, waxy material (sebum) via the differentiation and disintegration of fully mature cells, a unique process termed holocrine secretion [3-8]. Sebum is a group of complex lipids including triglycerides and fatty acid breakdown products, wax esters, squalene, cholesterol esters and cholesterol [9-13] (Fig. 1). Histologically, sebocytes are most commonly identified by lipophilic dyes such as Oil Red O, Nile Red and Sudan IV or immunostaining against lipogenic enzymes, specific keratins, and lipid-droplet associated proteins such as the perilipins [14-17] (Table 1).

There are also several examples of "free" (not associated with hair follicles) lipid producing glands. Examples include the Meibomian glands (eyelids), Fordyce's spots (oral epithelium), and the ceruminous glands (ears). The accumulation in uncovered skin area probably represents a reminiscence of the major SG task during species development: to coat the fur with sebum as a hydrophobic protection against overwetting and for heat insulation $[5,18]$. In the modern Homo sapiens, this functions as well as the responsibility for the release of pheromones used for territorial marking and sexual attraction $[5,8]$ are of limited importance. This fact and the tight association of increased SG activity with a common disease, acne vulgaris, led to the former suggestion that the SG itself is a reminiscence of human development, a "living fossil with a past but no future" [5]. This pessimistic approach made the SG an overall limited and less attractive field to work in.

The composition of sebum and the functions of SG are species-specific, making the human $S G$ an organ with a unique role. The lack of an ideal animal model compatible to human SGs was surmounted in the last 10 years by the development of experimental models for the in vitro study of human SGs [14-16, 19]. The latter have led to the identification of several, unknown or disregarded functions and finally to the complete revision of the SG role in human skin [20, 21]. On the other hand, several medical conditions have been associated with the SG $[14,18,22]$ (Table 2). Currently, the SG has come to the center of attention for researchers in order to both develop new treatment strategies targeting the molecular mechanisms and pathways involved in the pathogenesis of SG and SG-associated diseases and to understand sebaceous lipogenesis 
and differentiation [23]. Moreover, attention has lately been focused on identifying and understanding the complex endocrine properties of the SG and the role of the several hormone receptors present on sebocytes [24, 25] (Figs. 2, 3).

Sebaceous lipids contribute to a normally functional skin barrier. Alterations in the synthesis and composition, may contribute in the pathogenesis of inflammatory skin manifestations. $A$ marked reduction of sebaceous lipids, but also a significant increase in keratinocyte lipids, have been demonstrated in pediatric and adult patients with atopic dermatitis correlated with a decrease of sebocyte proliferation and prolongation of the S- phase in SG [26]. Moreover, in acne patients the incidence of constitutional eczema is significant lower than that occurring in the general population [27].

Here, we will review basic aspects of sebocyte molecular genetics and development and focus on new developments on the regulation of sebocyte differentiation beyond acne.

\section{Wnt and hedgehog signals govern the sebaceous lineage fate}

While several molecular networks and signalling pathways are important in balancing epidermal growth and differentiation [28], the signals for sebocyte development are only partially understood. Among them, $\beta$-catenin, transcription factor 3 (Tcf3) and lymphoid enhancer-binding factor-1 (Lef-1) seem to be of key importance. High levels of $\beta$-catenin stimulate the formation of hair follicles and low levels that of epidermis and sebaceous glands [29-31].. Lef-1 and Indian hedgehog $(\mathrm{IHH})$ seem to cooperate to control proliferation and differentiation of sebocyte progenitors [32]. In contrast, SHH/Gli-signaling has been suggested to be specifically required for sebocyte development [33]. Therefore, more experimental data for normal sebocyte lineages are required to resolve the role and functional contribution of individual hedgehogs for sebocyte progenitor cell development and the interaction between Wnt and hedgehog signaling. Other molecules implicated in sebocyte development include c-Myc, peroxisome proliferator-activating receptors (PPAR) and cyclooxygenase-2 [4, 23, 34] (Table 3).

\section{Unipotent resident progenitor cells may be responsible for the continuous sebocyte turnover}

The constant sebocyte turnover requires a continuous source of cells to maintain the gland, suggesting the involvement of stem cells. Currently available data on the epidermal stem cell compartment are consistent with the existence of a discrete population of SG stem cells in addition to those of the interfollicular epidermis and hair follicle bulge [35-37]. Of the different populations of epithelial stem cells of the skin, that of the SG is the least well characterized. There is good evidence for interdependence of the SG and hair follicle: in response to injury or other appropriate stimuli, stem cells in each location can generate all differentiated epithelial lineages [38] and in situations in which one organ collapses the other is also often lost [39]. The 
development of androgenetic alopecia [38] and of chemotherapy-induced effluvium [39] could be well explained by this mechanism.

While hair follicle bulge stem cells have the capacity to differentiate and produce SGs, there is evidence suggesting that under steady state conditions local environmental cues restrict the lineages selected by stem cell progeny and that a resident pool of progenitor cells exists within the SG $[35,40]$. For example, retroviral lineage tracing experiments in mouse skin revealed that the SG can be marked specifically over multiple hair cycles, supporting the notion that a population of long-living cells can maintain the SG independent of the hair follicle bulge [41]. Pulse-chase experiments in mouse skin further suggested the existence of slow-cycling cells in the gland [34]. Genetic lineage tracing experiments showed that cells expressing the transcriptional repressor Blimp1 [42] are progenitors that give rise to all cells within the sebaceous gland. Research in this field is still ongoing as evidenced by current contradictory findings [23, 35], whereby Blimp1 is not selectively expressed in sebaceous gland progenitor cells, but is also expressed by terminally differentiating cells in the interfollicular epidermis, sebaceous gland and hair follicle[40, 43]. While Blimp1 binds to and negatively regulates the c-Myc promoter [42], there is no correlation between Blimp1 and c-Myc levels in individual human sebaceous cells, suggesting that additional factors regulate levels of c-Myc protein in sebocytes [40].

\section{Sebaceous differentiation is a continuous process of stage repetition}

The earliest sebaceous differentiation is observable at 13-15 weeks of gestation in humans fetuses [18]. Sox9 is the earliest known signal necessary for SG and HF development [23, 44]. In its absence, cells expressing the putative sebocyte stem cell marker Blimp1 fail to appear. SGs at this early stage are already functional, contributing to the vernix caseosa. It has in fact been proposed that sebum is the first demonstrable glandular product of the human body [23]. While sebocyte differentiation is a continuous process, up to five distinct morphologic stages, reflecting the different differentiation steps, have been recognized [23, 45]. Another classical classification distinguishes three different zones. The peripheral zone is composed of flattened or cuboidal cells and forms about $40 \%$ of the gland [23, 46, 47]. These undifferentiated cells have a high nucleocytoplasmic ratio, are in contact with the basal lamina, and are mitotically active. Their cytoplasm is rich in tonofilaments, free ribosomes and mitochondria, but smooth endoplasmatic reticulum and Golgi complex are rare. Cells in the maturation zone contain enlarged cells bearing lipid droplets, well-developed smooth endoplasmatic reticulum and Golgi apparatus, and increasing numbers of lysosomes. The maturation zone also represents $\sim 40 \%$ of the SG $[23,47]$. As differentiation advances, cells progressively accumulate lipids and experience an extraordinary increase in volume of up to 150 times $[23,45]$. The necrosis zone represents $\sim 20 \%$ of the SG. Its cells are distorted due to the lipid load. The nuclei are substantially reduced in size, organelles are generally unrecognizable, and the cells are shortly before or already in the process of degeneration and release of their cellular contents [23, 47]. 


\section{Sebum is characterized by specific lipid fractions of sebaceous origin}

Human sebum contains mainly triglycerides, diglycerides and free fatty acids (40-60\% of total lipids), followed by wax esters (25-30\%), squalene (12-15\%), cholesterol esters (3-6\%) and cholesterol $(1.5-2.5 \%)[6,9,12]$. The lipid content of sebum is species specific. In addition, the relative amount of the components also vary greatly among humans at different ages. Wax esters and squalene are typical for sebocytes and are normally not produced elsewhere in the body.

Sebocytes possess a competent enzymatic machinery for the synthesis of all the lipid classes present in the sebum [48] (Table 4) but can also take up preformed lipids or remodel lipids from the bloodstream. The synthesis starts by the incorporation of different precursors including acetate, glucose, and aminoacids. Enzymes that form part of the cholesterol synthesis pathway, and of long chain fatty acids and their ester derivatives have been characterized as well as the regulation by the supply of exogenous lipids $[9,10]$.

\section{Fatty acids}

Sebum fatty acids are characterized by a large diversity including linear and branched species with odd or even carbon number, long chain and unusual unsaturations [9, 49,50]. Acetate, proprionate, isobutyrate, isovalerate, and 2-methyl-butyrate are used to produce the different fatty acids by extension with the addition of 2-carbon moieties derived from the malonyl-CoA. Desaturation occurs by the activity of the $\Delta 6$ and $\Delta 9$ desaturase. $\Delta 6$-desaturase is a functional marker of differentiated sebocytes [51]. It is detectable in cells with a full lipid synthetic capacity occupying the suprabasal layers of the SG. This pathway is unique to the human sebum and leads to the formation of specific fatty acids of sebum such as sapienic acid $(16: 1, \Delta 6)$ and sebaleic acid $(18: 2, \Delta 5,8)[10,23,51]$. Altered $\Delta 6$-desaturase activity has been associated with acne [10] leading to an increase of the sapienic acid content in both free and esterified moieties. Accumulation of $\Delta 9$ isoforms of monounsaturated fatty acids may occur in undifferentiated cells in the basal layer of the SG [52]. During the process of differentiation, $\Delta 6$ unsaturated fatty acids progressively accumulate and lead to a reduction of the $\Delta 9$ lipid content to less than $0.5 \%$.

Linoleic acid is considered to be directly involved in the sebaceous lipid synthesis and incorporated in the epidermal lipids of the infundibulum. Through the activation of $\beta$-oxidation, linoleic acid is transformed into two-carbon precursors which yields acetyl-CoA, the starter of the biosynthetic pathway, which leads to squalene and wax esters formation [53]. Since linoleic acid is an essential fatty acid, its plasma levels likely regulate its concentration in the sebocytes. Fatty acids are subsequently used to synthesize triglycerides, cholesterol and wax esters.

\section{Cholesterol and squalene}

Cholesterol and squalene share the initial steps of their biosynthesis. Squalene synthase catalyzes head-to-head condensation of two molecules of farnesyl pyrophosphate to yield 
squalene that must be converted to squalene 2,3-epoxide by the enzyme squalene oxidocyclase for cholesterol synthesis to continue. Squalene is the last linear intermediate in cholesterol biosynthesis, and in other tissues it is rapidly converted to lanosterol and finally to cholesterol by squalene oxidocyclase. Oxygen is needed to catalyze the reaction, and because the SG has an anaerobic environment this may be a rate-limiting step for the conversion to cholesterol and a possible reason of squalene accumulation. The amount of skin cholesterol has no apparent relation with plasma level [10] but is affected by the cholesterol levels in the SG environment. SGs respond to higher levels of lipoproteins by lowering the lipogenic capacity through inhibition of the HMG-CoA reductase activity. Moreover, the decline in production of sebum with age can be at least in part due to a lower activity of HMG-CoA reductase in older subjects.

\section{Glycerol, wax and sterol esters}

Triglycerides are synthesized from fatty acids and glycerol. Acyl CoA:diacylglycerol acyltransferases (DGAT) 1 and 2 are the key enzymes that catalyze the final step in the synthesis. Wax esters are produced in a two-step process involving a fatty-acyl-CoA reductase and wax synthase enzymes. Saturated fatty acids are preferentially included over its monounsaturated. Two acyl-CoA wax alcohol acyltransferase (AWAT 1 and 2) have been identified, the latter one primarily expressed in the cytoplasm of undifferentiated peripheral sebocytes. Esterification of cholesterol seems to be an evolutionary mechanism favoring the storage of sterols in the cytoplasm. The enzymes acyl-CoA cholesterol acyltransferase 1 (ACAT 1 ) is highly expressed in the SG, where it allows for the incorporation of cholesteryl esters into cytoplasmic lipid droplets [10].

\section{Complex lipid fractions can be identified by sebum lipidomics}

The lipidomic analysis represents a new approach for understanding the complex lipid matrix of the sebum with a broad range of chemical functionalities and expression levels. The identification of the composing species as intact molecules is a suitable analytical approach to find variations in the sebum composition $[9,53,54]$. Information regarding preferential arrangement of fatty acids in complex lipids can be collected and contribute to the understanding of the role of alterations of sebum composition in the pathologies of the PSU [10].

\section{Sebaceous duct (SD) cells are bimodal epithelial cells}

The sebum released from sebocytes drains into the SD. The SD encompasses sebocytes and is lined by keratinizing stratified squamous epithelium. As SD cells keratinize, they produce horny materials in the lumen with relatively low numbers of lipid droplets, which do not coalesce [55]. The boundary between undifferentiated sebocytes and SD cells is unclear. The SD is a transitional zone between infundibulum (interfollicular epidermis) and sebocytes, suggesting that a bimodality of these cells to differentiate into both directions exists [56]. In wounds, 
undifferentiated ductal cells migrate to the surface and differentiate into epidermal keratinocytes, and some undergo conversion into sebocytes [57]. A recent study identified keratin 6 as a marker of duct fate in SGs [58].

\section{Sebum composition and production are controlled by multiple factors PPAR}

PPAR are members of the nuclear hormone receptor (NHR) family and act as transcriptional regulators of a variety of genes including those involved in lipid metabolism in adipose tissue, liver and skin [59]. PPAR bind to cognate DNA elements called PPAR response elements in the 5'flanking region of target genes. Like many other NHR, they bind DNA as obligate heterodimers by partnering with one of the retinoid X receptors (RXRs) [59]. PPARY / RXRa and Liver-X receptor $(L X R)$ / RXRa promoter interactions are of crucial importance for the regulation of key genes of lipid metabolism. While various fatty acids, eicosanoids and prostanoids activate PPARs, oxysterols and intermediate products of the cholesterol biosynthetic pathway activate LXRs. There are three subclasses of PPAR in humans: $\alpha, \delta$, and $\gamma$, which differ in their tissue localization and in their transcriptional activities. PPARs are expressed in human SGs [24, 60] and in human SZ95 sebocytes [14, 60, 61]. Treatment of these cells with linoleic acid, a ligand for PPAR $\delta$ and $y$, increases the intracellular content of lipids [60]. Arachidonic acid couples to PPARy to induce differentiation and lipid production in human sebocytes [62, 63]. However, the activity of PPAR agonists seems to be complex: PPARy agonists have been shown to increase sebum production in adults with diabetes and hyperlipidemia [64]. In contrast, PPARa agonists seem to inhibit sebaceous lipogenesis [65] through prevention of the activation of the proinflammatory leukotriene pathway [66]. Moreover, PPAR agonists, especially that for PPARס, exhibit anti-apoptotic activity on human sebocytes by inducing the activation of PKB/Akt and p44/42, two kinases involved in anti-apoptosis and proliferation, respectively and by suppressing histone-associated DNA fragments [67]. These data indicate that PPAR $\alpha$ agonists and PPARY antagonists may reduce sebaceous lipid synthesis and, as such, may be useful in the treatment of acne. On the other hand, PPARy agonists may be beneficial in ageing skin, while PPARס agonists may be involved in sebaceous tumorigenesis.

\section{$\underline{\operatorname{LXR}}$}

LXRs, which are members of the NHR family play a critical role in cholesterol homeostasis and lipid metabolism [24, 68]. Treatment of SZ95 sebocytes with the LXR ligands TO901317 or 22(R)hydroxycholesterol enhanced accumulation of lipid droplets in the cells which could be explained through induction of the expression of the LXRa receptor and known LXR targets, such as fatty acid synthase and sterol regulatory element-binding protein-1 (SREBP-1) [49, 69]. 
FoxO1 is expressed in most lipid metabolizing cells, including prostate, liver, fat tissue, and the skin [70]. While human sebocytes may also express FoxO1, few relevant data exist until now [71, 72]. In adipocytes, FoxO1 directly interacts with PPARy to inhibit adipocyte differentiation and substantial evidence indicate a pivotal role FoxO1 in lipid homeostasis, regulation of oxidative stress, cell differentiation and apoptosis [70]. It has been proposed that acne and increased sebaceous lipogenesis are associated with a relative nuclear deficiency of FoxO1 caused by increased growth hormone (GH)/insulin/IGF-1/or FGFR2 signaling [72].

\section{$\underline{\text { Histamin }}$}

Sebaceous function can be also significantly modified by histamin and antihistamines [68]. Immunohistochemical analysis of frozen sections from normal human SGs revealed the presence of $\mathrm{H} 1$ receptors, demonstrating the potential for histamine receptor-mediated acne treatment through receptor antagonist activity in sebocytes [73]. In the same study diphenhydramine, a $\mathrm{H} 1$ receptor antagonist, significantly decreased squalene levels in human SG cells as determined by means of high-performance chromatography.

\section{$\underline{\text { Retinoids }}$}

Retinoids influence on the biological function of sebocytes is well known. Retinoic acid receptors (RAR; isotypes $\alpha$ and $y$ ) and retinoid $X$ receptors (RXR; isotypes $\alpha, \beta, y$ ) are expressed in human sebocytes [74]. The natural ligands for RAR and RXR are all-trans retinoic acid and 9-cis retinoic acid. In SZ95 sebocytes, 13-cis retinoic acid may unfold its action through a marked isomerisation to all-trans retinoic acid. All three compounds, all-trans retinoic acid, 13-cis retinoic acid and 9-cis retinoic acid exhibit anti-proliferative effects [74] and inhibit sebocyte differentiation and lipid synthesis [75]. RXR agonists stimulate sebocyte differentiation and proliferation [76]. RXR agonist in combination with specific PPAR agonists may exhibit a limited cooperation in affecting differentiation and growth in cultured primary sebocyte-like rat preputial cells [77].

\section{$\underline{\text { Structural proteins }}$}


During sebogenesis lipids are stored in vesicles called Lipid droplets (LD) are limited by a membrane containing phospholipids protein and enzymes. The most relevant membrane proteins are the perilipin (PLIN) family, which possesses structural and regulatory properties. In particular, PLIN2, the major form expressed during the differentiation process, regulates the gland size in vivo and regulates sebaceous lipid accumulation [78]. Experimental down-modulation of the expression significantly modify the composition of neutral lipids with a significant decrease in the unsaturated fatty acid component due to a marked decrease in the expression of specific lipogenic enzymes. On the other hand, PLIN3 has currently been shown to modulate specific lipogenic pathways in human sebocytes [79]. Another structural protein, angiopoietin-like 4, is strongly induced during sebocyte differentiation and regulates sebaceous lipogenesis [80].

\section{The function of sebaceous glands is controlled by various factors in health and disease}

\section{Sex steroids}

Three components of sebocyte function - differentiation, proliferation and lipid synthesis - are controlled by complex endocrinologic mechanisms. The skin, and especially the SG, are important sites of formation of actives androgens [81]. Enhanced SG activity is attributed to the potent androgen $5 \alpha$-dihydrostestosterone ( $5 \alpha-D H T)$, since SG cells possess all necessary enzymes for conversion of testosterone to $5 \alpha-\mathrm{DHT}$ [81]. The isoenzyme $5 \alpha$-reductase type I, which catalyses the conversion from testosterone to $5 \alpha-\mathrm{DHT}$ in peripheral tissues by a NADPHdependent reaction is expressed predominantly in the skin. It is present in the cytoplasm and cell membrane compartment in skin cells[82] and particularly in facial sebocytes [81], illustrating the key role of SG cells in androgen metabolism.

Testosterone and $5 a-D H T$ regulate SG function through binding to the nuclear androgen receptor $(A R)$ [83]. $A R$ is a member of the steroid superfamily of ligand-dependent transcription factors. $5 \alpha-D H T$ binds to the AR with greater affinity than testosterone and the $5 \alpha-D H T / a n d r o g e n$ receptor complex appears to be more stable and, therefore, more effective. AR is stabilized and upregulated by ligand binding; its downregulation reduces sebocyte proliferation [83, 84]. A dosedependent induction of sebocyte proliferation by testosterone treatment and no effect on lipid stimulation has been demonstrated [15]. The effect of androgens on sebaceous lipids is mediated by PPAR ligands $[85,86]$. Estrogens exhibit an inhibitory effect on excessive SG activity in vivo [87].

The $A R$ is not exclusively regulated by androgens which interact with the ligand binding domain of the AR. The N-terminal AF-1 function of AR is most important for the transcriptional control of the AR and mediates the impact of most coregulatory proteins on AR transactivation. More than 150 coregulatory proteins modulating AR transcriptional activity have been identified [88]. 


\section{Growth factors}

GH and IGF-I: The increased serum GH levels in acromegaly are associated with enhanced sebum secretion [88], an observation that was confirmed by GH treatment of human sebocytes in vitro [89]. In acne vulgaris, increased sebum production peaks in mid-adolescence at a time when GH and IGF-I reach their highest serum levels [89]. Increased serum levels of IGF-I have been observed in adult women and men with acne and the number of total acne lesions, inflammatory lesions, serum levels of $5 a-D H T$ and dehydroepiandrosterone sulphate (DHEAS), each correlated with serum IGF-I levels in women with acne [90]. IGF-I plays a key role in the induction of lipid synthesis in human sebocytes [91, 92]. IGF-I increases lipogenesis by inducing SREBP-1 [50] through activation of PI3K/Akt and MAPK/ERK-signal transduction pathway [93]. SREBP-1 preferentially regulates genes of fatty acid synthesis [93]. In addition, an interaction between IGF-I and estradiol has been described in SZ95 sebocytes, implicating that estrogens may have an indirect effect on the pathogenesis of sebaceous gland diseases [91].

Fibroblast growth factor receptor-2b (FGFR-2b) signaling: Androgen-mediated upregulation of FGFR-2b signaling in acne-prone skin has been proposed in the pathogenesis of acne vulgaris [94]. Acneiform nevus, which is a variant of nevus comedonicus, has been shown to be associated with Ser252Trp-gain-of-function mutation of FGFR2, which also explains acne in Apert syndrome [95]. In organotypic skin cultures, keratinocyte-derived interleukin-1a stimulated fibroblasts to secrete FGF7 which stimulated FGFR2b-mediated keratinocyte proliferation. Postnatal deletion of FGFR2b in mice resulted in SG atrophy [96]. The importance of FGFR2b in SG physiology is further supported by the mode of action of several anti-acne agents which have been proposed to attenuate FGFR2b-signaling [97].

\section{Nerves and neuropeptides regulate sebocyte function, inflammation and innate immunity} Little is known about the innervation of the SG

To synthesize large amounts of lipids and other substances such as hormones, the SG depends on a rich nutrient supply by blood vessels. Accordingly, rich vascularization and micro-circulation of SGs have been demonstrated in the past $[98,99]$. In contrast, the innervation of the SG has been the subject of controversy. Although a network of nerve fibers encircle the hair follicle and is tangent to the SG, the presence of nerve fibers actually entering the SG has only once been convincingly demonstrated in association with acne-involved SG [98-100].

\section{Neuropeptides}

Neuropeptides (NP) form a heterogeneous group of biologically active peptides that are present in neurons of both the central and peripheral nervous systems. However, human skin and in particular the SG have been shown to express functional receptors for neuropeptides, such as corticotropin-releasing hormone $(\mathrm{CRH})$, melanocortins, $\beta$-endorphin, vasoactive intestinal polypeptide, neuropeptide $Y$ and calcitonin gene-related peptide [68, 74]. Circadian secretion of 
$\mathrm{CRH}$ from the hypothalamus affects the pituitary gland. The latter synthesizes propiomelanocortin (POMC) and decomposes it into corticotropin (ACTH), $\beta$-endorphin as well as $\alpha$-melanocytestimulating hormone ( $\alpha-\mathrm{MSH}$, melanocortin) [68].

\section{$\underline{\mathrm{CRH}}$}

Activation of the $\mathrm{CRH}$ receptor 1 (CRHR-1) affects immune- and inflammatory processes and is involved in the development and the stress-induced exacerbation of acne. $\mathrm{CRH}$-binding protein (CRHBP) has a buffering role in response to the stress attack in acne by serving as a negative regulator of local $\mathrm{CRH}$ availability. $\mathrm{CRHR}-1$ seems to be an important receptor for the eccrine sweat glands and may have a direct role in the regulation of local dermal secretory activity. On the other hand, CRHR-2 exhibits the most significant expression within SGs and possibly regulates local SG functions by having a direct influence on sebum production [101]. In addition, $\mathrm{CRH}$ significantly induces sebaceous lipids production, IL-6 and -8 synthesis and may up-regulate mRNA levels of $3 \beta$ - hydroxysteroid dehydrogenase $/ \Delta^{5-4}$ isomerase $[102,103]$.

\section{Melanocortin}

a-MSH was identified not only as sebotropin and pigmentation hormone but also as a modulator of inflammatory and immune tissue responses within the PSU [104-106]. The effects of $\alpha-M S H$ are mediated via binding to melanocortin receptors (MC-R), which belong to the superfamily of Gprotein coupled receptors. The presence of both MC-1R and MC-5R, which bind $\alpha-M S H$, was detected in primary cell cultures of facial human sebocytes and in SZ95 sebocytes. The expression of MC-5R is weaker than that of MC1-R but it has been shown to be a marker of human sebocyte differentiation, since its expression increases in lipid-containing sebocytes [106, 107]. As proinflammatory cytokines are up-regulated in acne lesions, sebocytes may respond to these signals with increased $\mathrm{MC}-1 \mathrm{R}$ expression, thereby generating a negative feedback mechanism for $\alpha-\mathrm{MSH}$ which exerts direct anti-inflammatory actions, i.e. inhibition of IL-1mediated IL-8 secretion [105, 106].

A connection between MC-1R activation by $\alpha-M S H$ and PPAR-y has been reported in cultured melanoma cells, dependent on the phosphatidylinositol signaling pathway [108]. Lipids generated in this signal pathway, such as linoleic acid and arachidonic acid and their lipoxigenase byproducts are the principal in mediators of signal transduction. The activation of the lipid mediated pathway through PPAR could subtend the capacity of $\alpha-\mathrm{MSH}$ to influence cell proliferation and differentiation in sebocytes and melanocytes as well as lipogenesis and the inflammatory process in sebocytes. Interestingly, sebocytes are likely to modulate melanocyte functions and may contribute to skin colour variation in sebaceous glands-rich body regions [109]. Moreover, variation of $\mathrm{MC}-1 \mathrm{R}$ expression may be associated with different rate of sebogenesis in the different skin phototypes [110]. 


\section{Cannabinoid receptors, substance P}

Cannabinoid receptors 1 and 2 are expressed in human SGs [111], whereas the CB2 and other prototypic endocannabinoids are present in SZ95 sebocytes and may induce lipid production and cell death in a dose-dependent manner [112]. These actions are selectively mediated by CB2coupled signaling involving the MAPK pathway.

Substance P, expressed in small nerves around the acne-involved SGs [100, 113], promotes the development of cytoplasmic organelles in sebocytes, stimulates proliferation and induces a significant increase of sebocyte size and SG volume. Substance P expression has also been associated with increased innervation around the acne-involved SGs [100]. The latter is related to increased expression of nerve growth factor in acne-prone SGs. The abundant IL-6 expression in inflammatory sebaceous glands is directly regulated by nerve growth factor [113]. Neutral endopeptidase, an ectopeptidase (see below) that degrades substance $P$, is highly expressed in the SGs of acne patients [100].

\section{Ectopeptidases}

Ectopeptidases dipeptidyl peptidase IV (DP IV or CD 26) and aminopeptidase N (APN or CD13), which have been shown to be involved in the degradation of several NPs, especially substance $P$ [114], have been found to be highly expressed in human sebocytes in vivo and in vitro [115]. Inhibitors of DP IV and APN can suppress proliferation and slightly decrease neutral lipids, but can also enhance terminal differentiation in SZ95 sebocytes.

\section{Antimicrobial peptides}

In addition to sebum production, SG also secrete antimicrobial peptides (AMPs) including human defensins (hBD-1 and hBD-2) [116], cathelicidin [117] and demcidin [118]. In particular, hBD-2 is expressed intensely in suprabasal layers, especially in pustules [119]. Certain Propionibacterium acnes species induce hBD-2 in human sebocytes [120]. Interestingly, hBD-1 and hBD-2 as well as bacterial antigens may play key roles in protecting the PSU from microbial invasion [121, 122]. indeed, the physiologic skin microflora is essential for the inhibition of virulent bacterial invasion [122]. Histone $\mathrm{H} 4$ may be a major component of the antimicrobial action of human sebocytes; its release may play an important role in skin innate immunity [123]. On the other hand, sebaceous fatty acids exhibit antibacterial and antifungal properties [121, 124-126] and enhance the innate immune defence of human sebocytes by upregulating hBD-2 expression [121, 127].

\section{Adipokines}

Adipokines, i.e. proteins that are synthesized and secreted primarily by adipocytes in response to various stimuli are responsible for mediating the inflammatory effects of the adipose tissue in the local tissue environment as well as to different organs via circulation. Importantly, SGs were identified also as a potential source for these proteins as histochemical studies revealed that in 
vivo SGs of healthy skin expressed adiponectin, IL-6, leptin, serpin E1 (also known as plasminogen activator inhibitor-1 [PAI-1] and endothelial plasminogen activator inhibitor), resistin and visfatin (also known as nicotinamide phosphoribosyltransferase). Notably, such adipokine expression pattern was observed also in acne involved skin as well as in other skin diseases suggesting that their relevance in the context of acne is most likely in the ability of sebocytes to secrete them in a stimulus dependent manner, such as TLR activators or potential therapeutically applied stimuli like retinoic acid. Moreover, considering the various biological roles for adipokines in skin homeostasis sebocytes could contribute to a wide range of functions such as hair growth, wound healing, tissue matrix formation and regulation of inflammation via these secreted adipokines. Taking into account the high amount of SG throughout the body, it is also intriguing to suppose that SG-derived adipokines could contribute not only to a local but also to a possible systemic inflammation and perhaps metabolic effects (similarly to that of seen in the case of the adipose tissue) [128]. Importantly, sebocytes were proved not just to be the source of but also to be potential targets for adipokines. Detecting the functionally active full-length form of the leptin receptor $(\mathrm{Ob}-\mathrm{Rb})$ on SGs suggests that sebocytes could respond also to leptin, the key adipokine which links nutritional status with neuroendocrine and immune functions. While leptin deficient (ob/ob) mice were found to exhibit an increased sebaceous gland size suggesting that leptin is involved in the lipid production/secretion of sebocytes [152], leptin treatment of SZ95 sebocytes led to a "pro-acne" change in the sebaceous lipid profile via increasing the amounts of unsaturated FAs, especially the FA 16:1/16:0 ratio which largely resembles the changes in the composition of sebum found in acne patients, in association with the enlargement of intracellular lipid droplets and the activation of various inflammatory signalling pathways such as STAT3 and NFkB. These results all support that leptin could be a possible contributor in linking nutrition with acne, however the conditions and the possible pathways still need to be confirmed in more details [129]..

In addition to sex steroid hormones and growth factors sebocytes express and secrete adipokines [128]. Steroid hormones fulfill their paracrine / autocrine roles by regulating keratinocyte proliferation and apoptosis, as well as inducing sebocytes to produce adiponectin, IL-6, resistin, leptin, serpin E1 and visfatin, which contribute to maintain skin homeostasis and regulate the inflammatory process [128, 129]. The cross-talk evidence for keratinocytes with sebocytes has been corroborated by the longer maintainance of epidermal integrity and proliferation potential of basal keratinocytes as well as reduction of the apoptosis under ex vivo co-culture of skin explants and SZ95 sebocytes [130]. Interestingly, during sebaceous lipogenesis differentially regulated microRNAs could be detected [131]. 
In its role as a barrier to environmental stress, including environmental toxic agents and UV light [132], the skin is supported by the SGs. Recent studies provided evidence that human SGs may play a key role in regulating skin detoxification.

UV radiation and natural and artificial chemicals induce oxidative stress, which regulates major signaling pathways of extrinsic skin aging and of certain skin diseases [133]. The skin surface lipid (SSL) film, a mixture of sebum and keratinocyte membrane lipids, is the first barrier against environmental stress [134]. Among the ingredients of SSL, squalene, a key biosynthetic precursor of cholesterol secreted by SGs, and a-tocopherol (vitamin E) secreted together with lipids from sebaceous gland, provide collaboratively antioxidant protection to the skin surface [135-137]. In addition, the by-products, squalene peroxides, produce during squalene oxidation, are considered to be involved in inflammatory and immunologically determined skin diseases, such as acne, atopic and seborrheic dermatitis as well as in skin cancerogenesis [138]. A recent study in China showed that the urban polulation has a lower squalene/lipid ratio than the rural one, which may mean that reduction of squalene is induced by environmental pollutants [137]. Moreover, squalene peroxides are proposed as a reliable marker of environmental pollutants in the skin [138].

Clinically, marked volume reduction or absence of SGs was observed in patients with dioxininduced chloracne; the latter been the marker of dioxin intoxication in humans [139]. Similar changes in SGs were also found in patients with hidradenitis suppurativa/acne inversa, in whom cigarette smoking is a high risk factor [140]. In addition, ex vivo studies also reported that dioxins and benzo(a)pyrene (BaP), representative toxicants found in environmental pollutants and cigarette smoke, strongly inhibited lipogenesis in human SZ95 sebocytes and reduced the size of SGs via activation of the aryl hydrocarbon receptor $(A h R)$ signaling pathway [141, 142]. AhR is a ligand-activated transcription factor that mediates a spectrum of toxic and biological effects of dioxins and related compounds [143] and SGs have been proposed to play a predominant role in the cutaneous metabolism of xenobiotics via the AhR signaling pathway.

The expression of AhR and its classical downstream gene CYP1A1, the metabolizing and activating enzyme for dioxins and related compounds, were stronger in the SGs than in the epidermis [144, 145]. CYPs contribute to a metabolic "shield" protecting the host from all kinds of chemicals not only in liver and intestine, but also in the skin, where they contribute to xenobiotics metabolism in the sebocytes [145, 146]. In addition, 2,3,7,8-tetrachlorodibenzo-p-dioxin (TCDD) diminished the size of SGs and lipid synthesis by switching the sebocyte lineage into a keratinocyte one [141]. This lineage switch is likely to be induced via AhR activation [141], since sebaceous lipid content and expression of markers of markers of sebaceous differentiation were found markedly induced in AhR-knockdown SZ95 sebocytes [142]. Therefore, AhR may considered as a bilateral modulator of sebaceous/keratinocyte differentiation pathways (Fig. 4). 


\section{Tools for studying sebocytes in vitro and in vivo}

Cell lines / Ex vivo models

Undoubtfully, an organ culture including intact SGs would represent the best model for the study of sebocytes in vitro. Unfortunately, available approaches show major shortcomings such as limited availability of material and limited maintenance in culture over time. On the other hand, while primary human sebocytes preserve key sebaceous characteristics, they can only be cultivated for a few passages and a large number of donors is required for obtaining a reasonable amount of material [16]. To overcome these drawbacks, the immortalized SG cell line SZ95 [15], as well as later ones, SEB-1 [48] and Seb-E6E7 [40], were developed. While these cell lines fulfill many criteria of a good SG model (androgen-responsiveness, production of lipids including wax esters and squalene, expression of typical sebocyte markers), they only undergo partially spontaneous complete differentiation. However, they are able to fully differentiate under certain circumstances in vitro [63] or ex vivo [130]. In spite of these drawbacks, these lines, and especially the newly developed human skin/SZ95 sebocytes ex vivo co-culture model, contribute decisively to the study of SG activity and its regulation.

\section{Mouse models}

Several spontaneous mutant mice with SG alterations have been of considerable value in studying SG biology and epidermal lipid production. A classical example is the asebia mouse, a strain with highly hypoplastic SGs and almost absent sebum production, originally described in the 1960s. In 1999, it could be demonstrated that the asebia phenotype is due to the genomic deletion of Scd1, a gene encoding a key enzyme for the synthesis of monounsaturated fatty acids [147]. The widespread generation of transgenic and knockout mice after 1980 produced a large number of mouse lines with alterations in SG development and function. Some particularly interesting examples are summarized in Table 3.

\section{Conclusions and prospects}

Stenn and colleagues suggested the "sebogenic hypothesis" of pilosebaceous development [148]. This hypothesis postulates that SGs were the first mammalian skin appendages to develop during the evolution (after nails) and that the hair shaft, at least initially, solely served as a wick to draw sebum to the skin surface and disperse it there to enhance skin epidermal barrier. This hypothesis illustrates the increasing importance attributed to this gland and may explain why the hair shaft cannot survive without an active SG $[39,122,148]$. In addition, SGs are likely to play a key role in regulating skin detoxification stimulated by external chemical and physical stimuli, which is realized not only by peroxided squlalene and vitamin E secreted by SGs, but also interfering into an abnormal sebocyte differentiation via activation of the AhR signaling pathway. At last the detection of the proteom and the secretom of human sebocytes opens new horizons in understanding sebaceous lipidogenesis [149, 150]. Indeed, the SG has abandoned its traditional 
role as a battlefield of acne and has advanced towards an attractive model for studying highly topical aspects such as stem cell biology, cell differentiation, lipidomics, skin endocrinology and neuroendocrinology, and the innate immunity of the skin.

At the same time, several basic phenomena of SG biology remain unexplored. How does the SG maintain its stem cell population and how does the commitment towards differentiation take place? Are the lipid droplets of sebocytes perfect counterparts of these structures in adipocytes? Are specific microRNAs involved in the regulation of sebocyte differentiation and lipogenesis as shown for epidermal keratinocytes and adipocytes, respectively? Is the composition of sebum influenced by nutrition and does FoxO1 play a role in sebaceous differentiation? Further studies will also be necessary to evaluate the relevance of the many receptors localized on the surface of sebocytes and their true contribution to the gland function. New insights into these basic aspects of sebocyte biology may lead to the development of new therapeutical strategies for treating not only SG diseases but also several common skin diseases. 


\section{References}

1. Zouboulis CC, Tsatsou F. Anatomy of the sebaceous gland. In: Zouboulis CC, Katsambas AD, Kligman AM (eds) Pathogenesis and Treatment of Acne and Rosacea. Springer, Berlin, 2014:27-31.

2. Schneider MR, Schmidt-Ullrich R, Paus R. The hair follicle as a dynamic miniorgan. Curr Biol. 2009;19:R132-R142.

3. Zouboulis CC, Makrantonaki E. The role of the sebaceous gland. In: Zouboulis CC, Katsambas AD, Kligman AM (eds) Pathogenesis and Treatment of Acne and Rosacea. Springer, Berlin, 2014:77-90.

4. Schneider MR, Paus R. Sebocytes, multifaceted epithelial cells: lipid production and holocrine secretion. Int J Biochem Cell Biol. 2010;42:181-185.

5. Zouboulis CC, Baron JM, Bohm M, Kippenberger S, Kurzen H, Reichrath J, Thielitz A. Frontiers in sebaceous gland biology and pathology. Exp Dermatol. 2008;17:542-551.

6. Smith KR, Thiboutot DM. Thematic review series: skin lipids. Sebaceous gland lipids: friend or foe? J Lipid Res. 2008;49:271-281.

7. Zouboulis CC. Sebaceous gland in human skin - The fantastic future of a skin appendage. J Invest Dermatol. 2003;120:xiv-xv.

8. Thody AJ, Shuster S 1989 Control and function of sebaceous glands. Physiol Rev 69:383416.

9. Camera E, Ludovici M, Galante M, Sinagra JL, Picardo M Comprehensive analysis of the major lipid classes in sebum by rapid resolution high-performance liquid chromatography and electrospray mass spectrometry. J Lipid Res. 2010;51:3377-3388.

10. Picardo M, Ottaviani M, Camera E, Mastrofrancesco A. Sebaceous gland lipids. Dermatoendocrinol. 2009;1:68-71.

11. Pappas A. Epidermal surface lipids. Dermatoendocrinol. 2009;1:72-76.

12. Nikkari T. Comparative chemistry of sebum. J Invest Dermatol. 1974;62:257-267.

13. Ramasastry P, Downing DT, Pochi PE, Strauss JS. Chemical composition of human skin surface lipids from birth to puberty. J Invest Dermatol. 1970;54:139-144.

14. Zouboulis CC, Schagen S, Alestas T. The sebocyte culture - a model to study the pathophysiology of the sebaceous gland in sebostasis, seborrhoea and acne. Arch Dermatol Res. 2008;300:397-413.

15. Zouboulis CC, Seltmann H, Neitzel H, Orfanos CE. Establishment and characterization of an immortalized human sebaceous gland cell line (SZ95). J Invest Dermatol. 1999;113:1011-1020.

16. Xia LQ, Zouboulis CC, Detmar M, Mayer-da-Silva A, Stadler R, Orfanos CE. Isolation of human sebaceous glands and cultivation of sebaceous gland-derived cells as an in vitro model. J Invest Dermatol. 1989;93:315-321. 
17. Latham JA, Redfern CP, Thody AJ, De Kretser TA. Immunohistochemical markers of human sebaceous gland differentiation. J Histochem Cytochem. 1989;37:729-734.

18. Zouboulis CC, Fimmel S, Ortmann J, Turnbull JR, Boschnakow A. Sebaceous Glands. In: Hoath SB, Maibach HI (eds) Neonatal Skin - Structure and Function. $2^{\text {nd }}$ ed, Marcel Dekker, New York, 2003:59-88.

19. Zouboulis CC, Xia L, Akamatsu H, Seltmann H, Fritsch M, Hornemann S, Ruhl R, Chen W, $\mathrm{Nau} \mathrm{H}$, Orfanos $\mathrm{CE}$. The human sebocyte culture model provides new insights into development and management of seborrhoea and acne. Dermatology. 1998;196:21-31.

20. Zouboulis $\mathrm{CC}$, Chen W. The sebaceous gland and its role as an endocrine organ. World Clin Dermatol 2013;1(1):37-51.

21. Zouboulis CC. Sebaceous gland in human skin--the fantastic future of a skin appendage. J Invest Dermatol. 2003;120:xiv-xxv.

22. Chen W, Obermayer-Pietsch B, Hong JB, Melnik B, Yamasaki O, Dessinioti C, Ju Q, Liakou A, Al Khuzaei S, Katsambas A, Ring J, Zouboulis CC. Acne-associated syndromes: models for better understanding of acne pathogenesis. J Eur Acad Dermatol Venereol 2011; 25:637-646.

23. Zouboulis CC, Nikolakis G. Dessinioti C. Molecular aspects of sebaceous differentiation. In: Zouboulis CC, Katsambas AD, Kligman AM (eds) Pathogenesis and Treatment of Acne and Rosacea. Springer, Berlin, 2014:19-26.

24. Zouboulis CC, Sebaceous gland receptors. Dermatoendocrinol. 2009;1:77-80.

25. Chen W, Zouboulis CC. Hormones and the pilosebaceous unit. Dermatoendocrinol. 2009;1:81-86

26. Wirth H, Gloor M, Stoika D. Sebaceous glands in uninvolved skin of patients suffering from atopic dermatitis. Arch Dermatol Res. 1981; 270:167-169.

27. Shi VY, Leo M, Hassoun L, Chahal DS, Maibach HI, Sivamani RK. Role of sebaceous glands in inflammatory dermatoses. J Am Acad Dermatol. 2015;73:856-863.

28. Watt FM. The stem cell compartment in human interfollicular epidermis. J Dermatol Sci. 2002;28:173-180.

29. Niemann C, Owens DM, Hulsken J, Birchmeier W, Watt FM. Expression of DeltaNLef1 in mouse epidermis results in differentiation of hair follicles into squamous epidermal cysts and formation of skin tumours. Development. 2002;129:95-109.

30. Merrill BJ, Gat U, DasGupta R, Fuchs E. Tcf3 and Lef1 regulate lineage differentiation of multipotent stem cells in skin. Genes Dev. 2001;15:1688-1705.

31. Han G, Li AG, Liang YY, Owens P, He W, Lu S, Yoshimatsu Y, Wang D, Ten Dijke P, Lin X, Wang XJ. Smad7-induced beta-catenin degradation alters epidermal appendage development. Dev Cell. 2006;11:301-312. 
32. Niemann C, Unden AB, Lyle S, Zouboulis CC, Toftgard R, Watt FM. Indian hedgehog and beta-catenin signaling: role in the sebaceous lineage of normal and neoplastic mammalian epidermis. Proc Natl Acad Sci USA 2003; 100(suppl 1):11873-11880.

33. Allen M, Grachtchouk M, Sheng H, Grachtchouk V, Wang A, Wei L, Liu J, Ramirez A, Metzger D, Chambon $P$, Jorcano J, Dlugosz AA. Hedgehog signaling regulates sebaceous gland development. Am J Pathol. 2003;163:2173-2178.

34. Braun KM, Niemann C, Jensen UB, Sundberg JP, Silva-Vargas V, Watt FM. Manipulation of stem cell proliferation and lineage commitment: visualisation of label-retaining cells in wholemounts of mouse epidermis. Development. 2003;130:5241-5255.

35. Zouboulis CC, Adjaye J, Akamatsu H, Moe-Behrens G, Niemann K. Human skin stem cells and the ageing process. Exp Gerontol. 2008;43:986-997.

36. Fuchs E, Horsley V. More than one way to skin. Genes Dev. 2008;22:976-985.

37. Watt FM, Lo CC, Silva-Vargas V. Epidermal stem cells: an update. Curr Opin Genet Dev. 2006;16:518-524.

38. Ito M, Liu Y, Yang Z, Nguyen J, Liang F, Morris RJ, Cotsarelis G. Stem cells in the hair follicle bulge contribute to wound repair but not to homeostasis of the epidermis. Nat Med. 2005;11:1351-1354.

39. Selleri S, Seltmann H, Gariboldi S, Shirai YF, Balsari A, Zouboulis CC, Rumio C. Doxorubicin-induced alopecia is associated with sebaceous gland degeneration. $\mathrm{J}$ Invest Dermatol. 2006;126:711-720.

40. Lo Celso C, Berta MA, Braun KM, Frye M, Lyle S, Zouboulis CC, Watt FM. Characterization of bipotential epidermal progenitors derived from human sebaceous gland: contrasting roles of c-Myc and beta-catenin. Stem Cells. 2008;26:1241-1252.

41. Ghazizadeh S, Taichman LB. Multiple classes of stem cells in cutaneous epithelium: a lineage analysis of adult mouse skin. EMBO J. 2001;20:1215-1222.

42. Horsley V, O'Carroll D, Tooze R, Ohinata Y, Saitou M, Obukhanych T, Nussenzweig M, Tarakhovsky A, Fuchs E. Blimp1 defines a progenitor population that governs cellular input to the sebaceous gland. Cell. 2006;126:597-609.

43. Sellheyer K, Krahl D. Blimp-1: a marker of terminal differentiation but not of sebocytic progenitor cells. J Cutan Pathol. 2010; 37:362-370.

44. Nowak JA, Polak L, Pasolli HA, Fuchs E. Hair follicle stem cells are specified and function in early skin morphogenesis. Cell Stem Cell. 2008;3:33-43.

45. Tosti A. A comparison of the histodynamics of sebaceous glands and epidermis in man: a microanatomic and morphometric study. J Invest Dermatol. 1974;62:147-152.

46. Zouboulis CC, Krieter A, Gollnick H, Mischke D, Orfanos CE. Progressive differentiation of human sebocytes in vitro is characterized by increased cell size and altered antigenic expression and is regulated by culture duration and retinoids. Exp Dermatol. 1994;3:151160. 
47. Jenkinson DM, Elder HY, Montgomery I, Moss VA. Comparative studies of the ultrastructure of the sebaceous gland. Tissue Cell. 1985;17:683-698.

48. Thiboutot D, Jabara S, McAllister JM, Sivarajah A, Gilliland K, Cong Z, Clawson G Human skin is a steroidogenic tissue: steroidogenic enzymes and cofactors are expressed in epidermis, normal sebocytes, and an immortalized sebocyte cell line (SEB-1). J Invest Dermatol. 2003;120:905-914.

49. Hong I, Lee MH, Na TY, Zouboulis CC, Lee MO. LXRalpha enhances lipid synthesis in SZ95 sebocytes. J Invest Dermatol 2008;128:1266-1272.

50. Smith TM, Cong Z, Gilliland KL, Clawson GA, Thiboutot DM. Insulin-like growth factor-1 induces lipid production in human SEB-1 sebocytes via sterol response element-binding protein-1. J Invest Dermatol. 2006;126:1226-1232.

51. Ge L, Gordon JS, Hsuan C, Stenn K, Prouty SM. Identification of the delta-6 desaturase of human sebaceous glands: expression and enzyme activity. J Invest Dermatol. 2003;120:707-714.

52. Zouboulis CC, Jourdan E, Picardo M. Acne is an inflammatory disease and alterations of sebum composition initiate acne lesions. J Eur Acad Dermatol Venereol. 2014;28:527-532.

53. Pappas A, Anthonavage M, Gordon JS. Metabolic fate and selective utilization of major fatty acids in human sebaceous gland. J Invest Dermatol. 2002;118:164-171.

54. Robosky LC, Wade K, Woolson D, Baker JD, Manning ML, Gage DA, Reily MD. Quantitative evaluation of sebum lipid components with nuclear magnetic resonance. J Lipid Res. 2008;49:686-692.

55. Knutson DD. Ultrastructural observations in acne vulgaris: the normal sebaceous follicle and acne lesions. J Invest Dermatol. 1974;62:288-307.

56. Kurokawa I, Mayer-da-Silva A, Gollnick H, Orfanos CE. Monoclonal antibody labeling for cytokeratins and filaggrin in the human pilosebaceous unit of normal, seborrhoeic and acne skin. J Invest Dermatol. 1988;91:566-571.

57. Eisen AZ, Holyoke JB, Lobitz WC, Jr. Responses of the superficial portion of the human pilosebaceous apparatus to controlled injury. J Invest Dermatol. 1955;25:145-156.

58. Gu LH, Coulombe PA. Hedgehog signaling, keratin 6 induction, and sebaceous gland morphogenesis: implications for pachyonychia congenita and related conditions. Am J Pathol. 2008;173:752-761.

59. Berger J, Moller DE. The mechanisms of action of PPARs. Annu Rev Med. 2002;53:409435.

60. Alestas T, Ganceviciene R, Fimmel S, Muller-Decker K, Zouboulis CC. Enzymes involved in the biosynthesis of leukotriene B4 and prostaglandin E2 are active in sebaceous glands. $J$ Mol Med. 2006;84:75-87. 
61. Chen W, Yang CC, Sheu HM, Seltmann H, Zouboulis CC. Expression of peroxisome proliferator-activated receptor and CCAAT/enhancer binding protein transcription factors in cultured human sebocytes. J Invest Dermatol. 2003;121:441-447.

62. Dozsa A, Dezso B, Toth BI, Bacsi A, Poliska S, Camera E, Picardo M, Zouboulis CC, Bíró T, Schmitz G, Liebisch G, Rühl R, Remenyik E, Nagy L. PPARy nuclear receptor coupled arachidonic acid signaling is involved in differentiation and lipid production of human sebocytes. J Invest Dermatol. 2014;134:910-920

63. Wróbel A, Seltmann H, Fimmel S, Muller-Decker K, Tsukada M, Bogdanoff B, Mandt N, Blume-Peytavi U, Orfanos CE, Zouboulis CC. Differentiation and apoptosis in human immortalized sebocytes. J Invest Dermatol. 2003;120:175-181.

64. Trivedi NR, Cong Z, Nelson AM, Albert AJ, Rosamilia LL, Sivarajah S, Gilliland KL, Liu W, Mauger DT, Gabbay RA, Thiboutot DM. Peroxisome proliferator-activated receptors increase human sebum production. J Invest Dermatol. 2006;126:2002-2009.

65. Zouboulis CC, Nestoris S, Adler YD, Orth M, Orfanos CE, Picardo M, Camera E, Cunliffe WJ. A new concept for acne therapy: a pilot study with zileuton, an oral 5-lipoxygenase inhibitor. Arch Dermatol. 2003;139:668-670.

66. Zouboulis $\mathrm{CC}$, Seltmann H, Alestas T. Zileuton prevents the activation of the leukotriene pathway and reduces sebaceous lipogenesis. Exp Dermatol. 2010;19:148-150.

67. Schuster M, Zouboulis CC, Ochsendorf F, Muller J, Thaci D, Bernd A, Kaufmann R, Kippenberger S. Peroxisome proliferator-activated receptor activators protect sebocytes from apoptosis: a new treatment modality for acne? Br J Dermatol. 2011;164:182-186.

68. Zouboulis CC. The human skin as a hormone target and an endocrine gland. Hormones (Athens). 2004;3:9-26.

69. Russell LE, Harrison WJ, Bahta AW, Zouboulis CC, Burrin JM, Philpott MP. Characterization of liver $\mathrm{X}$ receptor expression and function in human skin and the pilosebaceous unit. Exp Dermatol. 2007;16:844-852.

70. Gross DN, van den Heuvel AP, Birnbaum MJ. The role of FoxO in the regulation of metabolism. Oncogene. 2008;27:2320-2336.

71. Mirdamadi Y, Thielitz A, Wiede A, Goihl A, Papakonstantinou E, Hartig R, Zouboulis CC, Reinhold D, Simeoni L, Bommhardt U, Quist S, Gollnick H. Insulin and insulin-like growth factor-1 can modulate the phosphoinositide-3-kinase / Akt/ FoxO1 pathway in SZ95 sebocytes in vitro. Mol Cell Endocrinol. 2015;415:32-44.

72. Melnik B, Zouboulis CC. Potential role of FoxO1 and mTORC1 in the pathogenesis of Western diet-induced acne. Exp Dermatol. 2013;22:311-315.

73. Pelle E, McCarthy J, Seltmann H, Huang X, Mammone T, Zouboulis CC, Maes D. Identification of histamine receptors and reduction of squalene levels by an antihistamine in sebocytes. J Invest Dermatol. 2008;128:1280-1285.

74. Zouboulis CC. Sebaceous gland receptors. Dermatoendocrinol 2009;1:77-80. 
75. Tsukada M, Schroder M, Roos TC, Chandraratna RA, Reichert U, Merk HF, Orfanos CE, Zouboulis CC. 13-cis retinoic acid exerts its specific activity on human sebocytes through selective intracellular isomerization to all-trans retinoic acid and binding to retinoid acid receptors. J Invest Dermatol. 2000;115:321-327.

76. Zouboulis CC, Korge B, Akamatsu H, Xia LQ, Schiller S, Gollnick H, Orfanos CE. Effects of 13-cis-retinoic acid, all-trans-retinoic acid, and acitretin on the proliferation, lipid synthesis and keratin expression of cultured human sebocytes in vitro. J Invest Dermatol. 1991;96:792-797.

77. Kim MJ, Deplewski D, Ciletti N, Michel S, Reichert U, Rosenfield RL. Limited cooperation between peroxisome proliferator-activated receptors and retinoid $\mathrm{X}$ receptor agonists in sebocyte growth and development. Mol Genet Metab. 2001;74:362-369.

78. Dahlhoff M, Camera E, Picardo M, Zouboulis CC, Chan L, Chang BH, Schneider MR. PLIN2, the major perilipin regulated during sebocyte differentiation, controls sebaceous lipid accumulation in vitro and sebaceous gland size in vivo. Biochim Biophys Acta Gen Subjects. 2013;1830:4642-4649.

79. Camera E, Dahlhoff M, Ludovici N, Zouboulis CC, Schneider M. Perilipin 3 modulates specific lipogenic pathways in SZ95 sebocytes. Exp Dermatol. 2014;23:759-761.

80. Dahlhoff M, Camera E, Picardo M, Zouboulis CC, Schneider MR. Angiopoietin-like 4, a protein strongly induced during sebocyte differentiation, regulates sebaceous lipogenesis but is dispensable for sebaceous gland function in vivo. J Dermatol Sci. 2014;75:148-150.

81. Fritsch M, Orfanos CE, Zouboulis CC. Sebocytes are the key regulators of androgen homeostasis in human skin. J Invest Dermatol. 2001;116:793-800.

82. Chen W, Zouboulis CC, Fritsch M, Kodelja V, Orfanos CE. Heterogeneity and quantitative differences of type 15 alpha-reductase expression in cultured skin epithelial cells. Dermatology. 1998;196:51-52.

83. Fimmel S, Saborowski A, Terouanne B, Sultan C, Zouboulis CC. Inhibition of the androgen receptor by antisense oligonucleotides regulates the biological activity of androgens in SZ95 sebocytes. Horm Metab Res. 2007;39:149-156.

84. Akamatsu $\mathrm{H}$, Zouboulis CC, Orfanos CE. Spironolactone directly inhibits proliferation of cultured human facial sebocytes and acts antagonistically to testosterone and 5 alphadihydrotestosterone in vitro. J Invest Dermatol. 1993;100:660-662.

85. Rosenfield RL, Deplewski D, Kentsis A, Ciletti N. Mechanisms of androgen induction of sebocyte differentiation. Dermatology. 1998;196:43-46.

86. Makrantonaki E, Zouboulis CC. Testosterone metabolism to 5alpha-dihydrotestosterone and synthesis of sebaceous lipids is regulated by the peroxisome proliferator-activated receptor ligand linoleic acid in human sebocytes. Br J Dermatol. 2007;156:428-432. 
87. Heemers HV, Tindall DJ, Androgen receptor (AR) coregulators: a diversity of functions converging on and regulating the AR transcriptional complex. Endocr Rev. 2007;28:778808.

88. Guy R, Ridden C, Kealey $\mathrm{T}$. The improved organ maintenance of the human sebaceous gland: modeling in vitro the effects of epidermal growth factor, androgens, estrogens, 13-cis retinoic acid, and phenol red. J Invest Dermatol. 1996;106:454-460.

89. Deplewski D, Rosenfield RL. Role of hormones in pilosebaceous unit development. Endocr Rev. 2000;21:363-392.

90. Cappel M, Mauger D, Thiboutot D. Correlation between serum levels of insulin-like growth factor 1, dehydroepiandrosterone sulfate, and dihydrotestosterone and acne lesion counts in adult women. Arch Dermatol. 2005;141:333-338.

91. Makrantonaki E, Vogel K, Fimmel S, Oeff M, Seltmann H, Zouboulis CC. Interplay of IGF-I and 17 beta-estradiol at age-specific levels in human sebocytes and fibroblasts in vitro. Exp Gerontol. 2008;43:939-946.

92. Deplewski D, Rosenfield RL. Growth hormone and insulin-like growth factors have different effects on sebaceous cell growth and differentiation. Endocrinology. 1999;140:4089-4094.

93. Smith TM, Gilliland K, Clawson GA, Thiboutot D. IGF-1 induces SREBP-1 expression and lipogenesis in SEB-1 sebocytes via activation of the phosphoinositide 3-kinase/Akt pathway. J Invest Dermatol. 2008;128:1286-1293.

94. Melnik BC. Role of FGFR2-signaling in the pathogenesis of acne. Dermatoendocrinol. 2009;1:141-156.

95. Melnik BC, Vakilzadeh F, Aslanidis C, Schmitz G. Unilateral segmental acneiform naevus: a model disorder towards understanding fibroblast growth factor receptor 2 function in acne? Br J Dermatol. 2008;158:1397-1399.

96. Grose R, Fantl V, Werner S, Chioni AM, Jarosz M, Rudling R, Cross B, Hart IR, Dickson C. The role of fibroblast growth factor receptor $2 b$ in skin homeostasis and cancer development. EMBO J. 2007;26:1268-1278.

97. Melnik BC, Schmitz G, Zouboulis CC. Anti-acne agents attenuate FGFR2 signal transduction in acne. J Invest Dermatol. 2009;129:1868-1877.

98. Montagna W, Parakkal PF. The Structure and Function of the Skin. Academic Press, London, 1974.

99. Montagna W, Kligman AM, Carlisle KS. Atlas of Normal Human Skin. Springer, Heidelberg, 1992.

100. Toyoda M, Nakamura M, Makino T, Kagoura M, Morohashi M. Sebaceous glands in acne patients express high levels of neutral endopeptidase. Exp Dermatol. 2002;11:241-247.

101. Ganceviciene R, Graziene V, Fimmel S, Zouboulis CC. Involvement of the corticotropinreleasing hormone system in the pathogenesis of acne vulgaris. $\mathrm{Br} \mathrm{J}$ Dermatol. 2009;160:345-352. 
102. Zouboulis CC, Seltmann H, Hiroi N, Chen W, Young M, Oeff M, Scherbaum WA, Orfanos CE, McCann SM, Bornstein SR. Corticotropin-releasing hormone: an autocrine hormone that promotes lipogenesis in human sebocytes. Proc Natl Acad Sci U S A. 2002;99:71487153.

103. Krause K, Schnitger A, Fimmel S, Glass E, Zouboulis CC. Corticotropin-releasing hormone skin signaling is receptor-mediated and is predominant in the sebaceous glands. Horm Metab Res. 2007;39:166-170.

104. Lipton JM, Catania A. Anti-inflammatory actions of the neuroimmunomodulator alpha-MSH. Immunol Today. 1997;18:140-145.

105. Bohm M, Schiller M, Stander S, Seltmann H, Li Z, Brzoska T, Metze D, Schioth HB, Skottner A, Seiffert K, Zouboulis CC, Luger TA. Evidence for expression of melanocortin-1 receptor in human sebocytes in vitro and in situ. J Invest Dermatol. 2002;118:533-539.

106. Ganceviciene R, Graziene V, Bohm M, Zouboulis CC. Increased in situ expression of melanocortin-1 receptor in sebaceous glands of lesional skin of patients with acne vulgaris. Exp Dermatol. 2007;16:547-552.

107. Zhang L, Li WH, Anthonavage M, Eisinger M. Melanocortin-5 receptor: a marker of human sebocyte differentiation. Peptides. 2006;27:413-420.

108. Maresca V, Flori E, Camera E, Bellei B, Aspite N, Ludovici M, Catricalà C, Cardinali G, Picardo M.Linking aMSH with PPARy in B16-F10 melanoma. Pigment Cell Melanoma Res. 2013;26:113-127.

109. Abdel-Naser MB, Seltmann H, Zouboulis CC. SZ95 sebocytes induce epidermal melanocyte dendricity and proliferation in vitro. Exp Dermatol. 2012;21:393-395.

110. Maresca V, Flori E, Picardo M. Skin phototype: a new perspective. Pigment Cell Melanoma Res. 2015;28:378-389.

111. Stander S, Schmelz M, Metze D, Luger T, Rukwied R. Distribution of cannabinoid receptor 1 (CB1) and 2 (CB2) on sensory nerve fibers and adnexal structures in human skin. $J$ Dermatol Sci. 2005;38:177-188.

112. Dobrosi N, Toth BI, Nagy G, Dozsa A, Geczy T, Nagy L, Zouboulis CC, Paus R, Kovacs L, Biro T. Endocannabinoids enhance lipid synthesis and apoptosis of human sebocytes via cannabinoid receptor-2-mediated signaling. FASEB J. 2008;22:3685-3695.

113. Toyoda M, Nakamura M, Morohashi M. Neuropeptides and sebaceous glands. Eur J Dermatol. 96;12:422-427.

114. Ansorge S, Reinhold D, Lendeckel U. Propolis and some of its constituents down-regulate DNA synthesis and inflammatory cytokine production but induce TGF-beta1 production of human immune cells. Z Naturforsch C. 2003;58:580-589.

115. Thielitz A, Reinhold D, Vetter R, Bank U, Helmuth M, Hartig R, Wrenger S, Wiswedel I, Lendeckel U, Kahne T, Neubert K, Faust J, Zouboulis CC, Ansorge S, Gollnick H. Inhibitors 
of dipeptidyl peptidase IV and aminopeptidase $\mathrm{N}$ target major pathogenetic steps in acne initiation. J Invest Dermatol. 2007;127:1042-1051.

116. Braff MH, Bardan A, Nizet V, Gallo RL. Cutaneous defense mechanisms by antimicrobial peptides. J Invest Dermatol. 2005;125:9-13.

117. Lee DY, Yamasaki K, Rudsil J, Zouboulis CC, Park GT, Yang JM, Gallo RL. Sebocytes express functional cathelicidin antimicrobial peptides and can act to kill propionibacterium acnes. J Invest Dermatol. 2008;128:1863-1866.

118. Dahlhoff M, Zouboulis CC, Schneider MR. Expression of dermcidin in sebocytes supports a role for sebum in the constitutive innate defense of human skin. J Dermatol Sci. 2016;81:124-126.

119. Chronnell CM, Ghali LR, Ali RS, Quinn AG, Holland DB, Bull JJ, Cunliffe WJ, McKay IA, Philpott MP, Muller-Rover S. Human beta defensin-1 and -2 expression in human pilosebaceous units: upregulation in acne vulgaris lesions. J Invest Dermatol. 2001;117:1120-1125.

120. Nagy I, Pivarcsi A, Koreck A, Szell M, Urban E, Kemeny L. Distinct strains of Propionibacterium acnes induce selective human beta-defensin-2 and interleukin- 8 expression in human keratinocytes through toll-like receptors. J Invest Dermatol. 2005;124:931-938.

121. Nakatsuji T, Kao MC, Zhang L, Zouboulis CC, Gallo RL, Huang CM. Sebum free fatty acids enhance the innate immune defense of human sebocytes by upregulating beta-defensin- 2 expression. J Invest Dermatol. 2010;130:985-994.

122. Georgel P, Crozat K, Lauth X, Makrantonaki E, Seltmann H, Sovath S, Hoebe K, Du X, Rutschmann S, Jiang Z, Bigby T, Nizet V, Zouboulis CC, Beutler B. A toll-like receptor 2responsive lipid effector pathway protects mammals against skin infections with grampositive bacteria. Infect Immun. 2005;73:4512-4521.

123. Lee DY, Huang CM, Nakatsuji T, Thiboutot D, Kang SA, Monestier M, Gallo RL. Histone H4 is a major component of the antimicrobial action of human sebocytes. J Invest Dermatol. 2009;129:2489-2496.

124. Nakatsuji T, Kao MC, Fang J-Y, Zouboulis CC, Zhang L, Gallo RL, Huang C-M. Antimicrobial property of lauric acid against Propionibacterium acnes: its therapeutic potential for inflammatory acne vulgaris. J Invest Dermatol. 2009;129:2480-2488.

125. Drake DR, Brogden KA, Dawson DV, Wertz PW. Thematic review series: skin lipids. Antimicrobial lipids at the skin surface. J Lipid Res. 2008;49:4-11.

126. Wille JJ, Kydonieus A. Palmitoleic acid isomer (C16:1delta6) in human skin sebum is effective against gram-positive bacteria. Skin Pharmacol Appl Skin Physiol. 2003;16:176187.

127. Zouboulis CC, Angres S, Seltmann H. Regulation of stearoyl-CoA desaturase and fatty acid desaturase 2 expression by linoleic acid and arachidonic acid in human sebocytes leads to 
enhancement of proinflammatory activity but does not affect lipogenesis. Br J Dermatol. 2011;165:269-276.

128. Kovács D, Lovászi M, Póliska S, Oláh A, Bíró T, Veres I, Zouboulis CC, Ståhle M, Rühl R, Remenyik É, Törőcsik D. Sebocytes differentially express and secrete adipokines. Exp Dermatol. 2016;25:194-199.

129. Töröcsik D, Kovács D, Camera E, Lovászi M, Cseri K, Nagy GG, Molinaro R, Rühl R, Tax G, Szabó K, Picardo M, Kemény L, Zouboulis CC, Remenyik E. Leptin promotes a proinflammtory lipid profile and induces inflammatory pathways in human SZ95 sebocytes. $\mathrm{Br} \mathrm{J}$ Dermatol. 2014;171:1326-1335

130. Nikolakis G, Seltmann H, Hossini A, Makrantonaki E, Knolle J, Zouboulis CC. Ex vivo human skin and SZ95 sebocytes exhibit a homeostatic interaction in a novel co-culture contact model. Exp Dermatol. 2015;24:497-502.

131. Schneider MR, Samborski A, Bauersachs S, Zouboulis CC. Differentially regulated microRNAs during human sebaceous lipogenesis. J Dermatol Sci. 2013;70:88-93.

132. Lee SH, Jeong SK, Ahn SK. An update of the defensive barrier function of skin. Yonsei Med J. 2006;47:293-306.

133. Masaki H. Role of antioxidants in the skin: anti-aging effects. J Dermatol Sci. 2010;58:8590.

134. De Luca C, Valacchi G. Surface lipids as multifunctional mediators of skin responses to environmental stimuli. Mediators Inflamm. 2010;321494.

135. Briganti S, Picardo M. Antioxidant activity, lipid peroxidation and skin diseases. What's new. J Eur Acad Dermatol Venereol. 2003;17:663-669.

136. Ekanayake-Mudiyanselage S, Thiele J. Die Talgdrüse als Transporter für Vitamin E. Hautarzt. 2006;57:291-296.

137. Lefebvre MA, Pham DM, Boussouira B, Qiu H, Ye C, Long X, Chen R, Gu W, Laurent A, Nguyen QL. Consequences of urban pollution upon skin status. A controlled study in Shanghai area Int J Cosmet Sci. 2015;[Epub ahead of print].

138. Pham DM, Boussouira B, Moyal D, Nguyen QL. Oxidization of squalene, a human skin lipid: a new and reliable marker of environmental pollution studies. Int $\mathrm{J}$ Cosmet Sci. 2015;37:357-365.

139. Panteleyev AA, Bickers DR. Dioxin-induced chloracne--reconstructing the cellular and molecular mechanisms of a classic environmental disease. Exp Dermatol. 2006;15:705730.

140. Kamp S, Fiehn AM, Stenderup K, Rosada C, Pakkenberg B, Kemp K, Dam TN, Jemec GB. Hidradenitis suppurativa: a disease of the absent sebaceous gland? Sebaceous gland number and volume are significantly reduced in uninvolved hair follicles from patients with hidradenitis suppurativa. Br J Dermatol. 2011;164:1017-1022. 
141. Ju Q, Fimmel S, Hinz N, Stahlmann R, Xia L, Zouboulis CC. 2,3,7,8-Tetrachlorodibenzo-pdioxin alters sebaceous gland cell differentiation in vitro. Exp Dermatol. 2011;20:320-325.

142. Hu T, Pan Z, Yu Q, Mo X, Song N, Yan M, Zouboulis CC, Xia L, Ju Q. Benzo(a)pyrene induces interleukin (IL)-6 production and reduces lipid synthesis in human SZ95 sebocytes via the aryl hydrocarbon receptor signaling pathway. Environ Toxicol Pharmacol. 2016;43:54-60.

143. Esser C. Biology and function of the aryl hydrocarbon receptor: report of an international and interdisciplinary conference. Arch Toxicol. 2012;86:1323-1329.

144. Ju Q, Yu Q, Song NJ, Tan Y, Xia LQ, Zouboulis CC. Expression of aryl hydrocarbon receptor in human epidermis, hair follicles and sebaceous glands and its significance. Chin J Dermatol. 2011;44: 761-764.

145. Rowe JM, Welsh C, Pena RN, Wolf CR, Brown K, Whitelaw CB. Illuminating role of CYP1A1 in skin function. J Invest Dermatol. 2008;128:1866-1868.

146. Paraskevaidis A, Drakoulis N, Roots I, Orfanos CE, Zouboulis CC. Polymorphisms in the human cytochrome P-450 1A1 gene (CYP1A1) as a factor for developing acne. Dermatololgy 1998;196:171-175.

147. Zheng Y, Eilertsen KJ, Ge L, Zhang L, Sundberg JP, Prouty SM, Stenn KS, Parimoo S. Scd1 is expressed in sebaceous glands and is disrupted in the asebia mouse. Nat Genet. 1999;23:268-270.

148. Stenn KS, Zheng Y, Parimoo S. Phylogeny of the hair follicle: the sebogenic hypothesis. J Invest Dermatol. 2008;128:1576-1578.

149. Dahlhoff M, Fröhlich T, Arnold GJ, Müller U, Leonhardt H, Zouboulis CC, Schneider M. Characterization of the sebocyte lipid droplet proteome reveals novel potential regulators of sebaceous lipogenesis. Exp Cell Res. 2015;332:146-155

150. Dahlhoff M, Fröhlich T, Arnold GJ, Zouboulis CC, Schneider NR. LC-MS/MS analysis reveals a broad functional spectrum of proteins in the secretome of sebocytes. Exp Dermatol. 2016;25:66-67

151. Magnusdottir E, Kalachikov S, Mizukoshi K, Savitsky D, Ishida-Yamamoto A, Panteleyev $A A$, Calame K. Epidermal terminal differentiation depends on $B$ lymphocyte-induced maturation protein-1. Proc Natl Acad Sci U S A. 2007;104:14988-14993.

152. Chen HC, Smith SJ, Tow B, Elias PM, Farese RV, Jr. Leptin modulates the effects of acyl CoA:diacylglycerol acyltransferase deficiency on murine fur and sebaceous glands. J Clin Invest. 2002;109:175-181.

153. Karnik P, Tekeste Z, McCormick TS, Gilliam AC, Price VH, Cooper KD, Mirmirani P. Hair follicle stem cell-specific PPARgamma deletion causes scarring alopecia. J Invest Dermatol. 2009;129:1243-1257.

154. Miyazaki M, Man WC, Ntambi JM. Targeted disruption of stearoyl-CoA desaturase1 gene in mice causes atrophy of sebaceous and meibomian glands and depletion of wax esters in 
the eyelid. J Nutr. 2001;131:2260-2268.

155. Jong MC, Gijbels MJ, Dahlmans VE, Gorp PJ, Koopman SJ, Ponec M, Hofker MH, Havekes LM. Hyperlipidemia and cutaneous abnormalities in transgenic mice overexpressing human apolipoprotein C1. J Clin Invest. 1998;101:145-152.

156. Arnold I, Watt FM. c-Myc activation in transgenic mouse epidermis results in mobilization of stem cells and differentiation of their progeny. Curr Biol. 2001;11:558-568.

157. Waikel RL, Kawachi Y, Waikel PA, Wang XJ, Roop DR. Deregulated expression of c-Myc depletes epidermal stem cells. Nat Genet. 2001;28:165-168.

158. Neufang G, Furstenberger G, Heidt M, Marks F, Muller-Decker K. Abnormal differentiation of epidermis in transgenic mice constitutively expressing cyclooxygenase-2 in skin. Proc Natl Acad Sci U S A. 2001;98:7629-7634.

159. Dahlhoff M, Muller AK, Wolf E, Werner S, Schneider MR. Epigen transgenic mice develop enlarged sebaceous glands. J Invest Dermatol. 2010;130:623-626. 


\section{Figure Legends}

Figure 1. Biosynthetic pathways involved in sebum production. Abbreviations: FA, fatty acids; WE, wax esthers; TG, DG, MG, tri-, di-, and monoglycerides; CE, cholesterol esthers.

Figure 2. Hormonal receptors in human skin. Human sebocytes express a wide range of hormone receptors, such as receptors for peptide hormones, neurotransmitters, steroid and thyroid hormones, which are found in the cytoplasm or nuclear compartment and thus, constitute appealing pharmaceutical targets to be approached. Modified from ${ }^{(54)}$.

Figure 3. Interaction between enzymes, membrane and nuclear receptors as well as their ligands in human sebocytes: their influence on lipid accumulation is displayed. The release of various hormones and inflammatory mediators are also seen. In red, future prospective drugs targeting elements of acne pathogenesis. $R$ receptor, $\mathrm{CRH}$ corticotrophin releasing hormone, $\alpha-\mathrm{MSH} \alpha$ melanocyte stimulating hormone, ACTH adrenocotricotropic hormone, IL interleukin, TNFa tumor necrosis factor- $\alpha$, 9cisRA 9-cis retinoic acid, atRA all-trans retinoic acid, LTB leukotriene, $A A$ arachidonic acid, $L A$ linoleic acid, $G H$ growth hormone, $N Y$ neuropeptide $Y, I G F-1$ insulin like growth factor-1, $P G$ prostaglandin, $D H T 5 \alpha$-dihydrotestosterone, $E R$ estrogen receptor, $A R$ androgen receptor, $R X R$ retinoid $\mathrm{X}$ receptor, $R A R$ retinoic acid receptor, PPAR peroxisome proliferators-activated receptor, LOX lipoxygenase, LTA4 hydrolase leukotriene A4 hydrolase, COX cyclooxygenase.

Figure 4. Bilateral modulation of sebocyte differentiation by AhR. The activation of AhR induces sebocyte differentiation towards a terminal keratinocyte lineage. In contrast, absence of AhR expression leads epithelial cells to an immature sebocyte status. 